flooded, and had to be abandoned; when the water receded the old camp had been sealed by layers of clay and a new camp was made. The same sequence of events recurred again and again, but on each occasion the returning stone industry represents a later phase of the culture. A sequence of Acheulean culture "such as exists nowhere else" is thus made available for study. Fossilized remains of extinct marnmals found here include many genera and species similar to those from Oldoway Gorge, TanganyikaElephas antiquus, the straight-tusked elephant, Hippopotamus gorgops, the hippopotamus with periscopic eyes, etc. All the bones which could contain marrow have been split to extract it, but there are no signs of fire.

Dr. Leakey's discovery would appear to open up a new vista in the study of the early stone age and will, with the discovery of the Rusinga jaw recently announced, prove of high importance in the annals of the study of primitive man. It may be pointed out, however, that a discovery very similar to that now recorded by Dr. Leakey, and also showing the cultural sequence, was made at Whitlingham, near Norwich, in 1926-27, when J. E. Sainty and H. Halls recovered from such parts of the site as they were able to excavate 543 specimens, ranging from Chellean to Mousterian, of which 173 were hand-axes or choppers, the majority Acheulean. Prof. P. G. H. Boswell, after examining the site, in reporting on the geological evidence, concluded that probably primitive man had camped and established his workshops here on gravel banks adjoining the old channel of the River Yare. Lest the reported statement that "the Acheulean or great hand-axe culture was first found in England by Sir John Frere in 1750" should be a trap for the unwary, it should be noted that it was in 1797 that John Frere, F.R.S. (1740-1807), the famous antiquary-he was neither knighted nor a baronet-discovered flints "evidently weapons of war" but now identified as Acheulean at Hoxne in Suffolk. The first recorded hand-axe found in Britain came from Gray's Inn Lane, London, in 1690 and is now in the British Museum.

Archæologists attending the fortheoming PanAfrican Congress on Prehistory at Nairobi in January next (Nature, April 20, p. 548) will have the advantage of discussing the evidence of Dr. Leakey's war-time discoveries, including the Rusinga jaw, on the actual ground. No doubt argument there will clarify the issues in the recent tendency of opinion on the place of man's origin to swing back from Asia to Africa. It should certainly serve to integrate the problems of African prehistory, and in particular to place recent discoveries in both East and South Africa in true perspective.

$$
1616
$$

\section{RESEARCH AND THE SMALLER FIRM IN BRITAIN}

A CONFERE weE arranged by the Manchester A Joint Resfarch Council on "Research and the Smallerfin at the Albert Hall, Manchester, on Ocfer 18, at which Dr. P. Dunsheath and Sir Eduhd Appleton presided over the morning and aftdroon sessions, respectively, was remarkable for a disinclination, as revealed in the discussion following the papers, to rely on large research organisations either of the type of the Mellon Institute or the Battelle Institute, on the ground that it is better for individual officers of small concerns to make themselves responsible for research. Opposition to institutions such as the Mellon Institute with its system of industrial fellowships sponsored by individual firms was brought to a focus in Dr. F. C. Toy's address at the afternoon session on "Existing and Potential Facilities for Research". In so far as the Mellon Institute is largely supported by the large firms, the soundness of the conception and the general confidence in the foundation can scarcely be questioned; nevertheless, Dr. Toy's paper indicated concern as to the future of the research association in Great Britain and its ability to win the confidence of the industry it served.

Mr. C. G. Renold's paper at the morning session, which was opened by Mr. A. H. S. Hinchcliffe, dealt with internal organisation for the application of research, and discussed more particularly the management factor which is involved, as well as a scientific attitude of mind on the part of the leaders of industry and adequate facilities for the prosecution of research, to enable industry in Britain to be more responsive to the discoveries of science. The management problem involves three phases-recognition, investigation and application-and the responsibility for pursuing such work in all phases should rest on one individual, designated by Mr. Renold as the 'development officer'. That officer's duties as regards recognition and investigation present no great difficulty from the point of view of organisation, though even here it is open to doubt whether he can be really effective unless he has the status of a director. His duties in regard to application involve relations with the manufacturing side of the business and call for special techniques and practices of management. Mr. Renold had mainly the engineering industry in mind, but what he had to say about a foundation of authoritative specifications for raw materials, products and processes based on consultation with all concerned would apply to other industries as well. Mr. Renold would vest in the development officer the custody and upkeep of such specifications and the chairmanship of consultations in either formulation or revision.

Dr. C. J. T. Cronshaw's paper, "Technical Servicethe Vital Link between the Producer and the Con. sumer", developed further some ideas implicit in his Mather Lecture to the Textile Institute last year, and he insisted that technical service has as its essential function the experimental investigation of the application of certain products within a consuming industry; its real value arises out of the unique knowledge acquired by research and experiment in its own laboratories. It is an abiding process of acquiring new knowledge, and it is not the function of technical service merely to provide a knowledge of the general science of chemistry, physics or engineering to a section of industry needing it. Dr. Cronshaw asserted that the function of technical service is to supply precise, specific and unique knowledge, and he then passed on to the quality of expert. ness. In doing so, he paid tribute to the skill and experience of the textile industry in Great Britain, and said that the only sure method of determining whether or not a new synthetic fibre would be a worthwhile addition to the range of fibres used by the textile industry is to put an appropriate quantity at the disposal of the industry and seek the initiative as well as the diversity of skill and talent of the firms within the industry. Sustained systematic search for novel products designed for some specific 
purpose involves inevitably a technical service department for the purpose of evaluating new products and serving as a link between the potential consumer and producer. While, however, a technical service can help and collaborate in the industrial use of new products, it cannot unaided solve completely the problems arising in different fields of industrial effort. The small firm can utilize technical service just as readily as the larger firm.

Sir Edward Appleton, speaking at the afternoon session, said that the Department of Scientific and Industrial Research has given much thought to the problems of research and the smaller firm. $\mathrm{He}$ suggested that the industrial research associations should form the main reservoirs of knowledge on which the smaller firms should draw, stressing particularly the importance of efficient distribution of knowledge, supplemented by personal contacts, and the value of membership of more than one research association. He referred in general terms to the universities and technical colleges as the main source of new knowledge and fundamental research, and stressed the importance of having within the smallest firm those competent to assess the bearing of new knowledge on the products, processes or purposes of that industry. When facilities and staff are available, the Department of Scientific and Industrial Research will be prepared to assist a small firm by arranging to carry out special investigations into specific problems, although it is not possible to offer the same facilities as the Mellon Institute or the Battelle Institute-a statement which appears to conflict with Dr. Toy's remark that the research associations themselves are not encouraged to undertake work at cost for an individual firm.

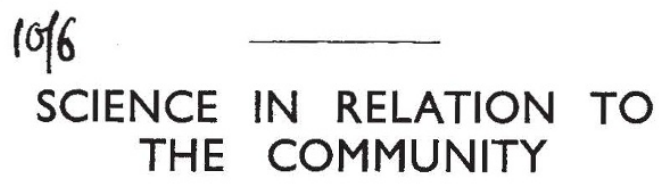

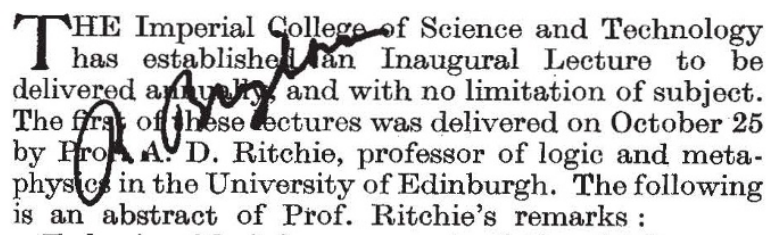

To begin with, it is necessary to distinguish between science and technology. In popular use, the term science covers both. Though one man's activities may be such as to count as both science and technology, this does not happen often. Even so, the aims of the two are always distinct. The man of science is trying to understand. His practical activities are practice for the sake of understanding. The technologist is concerned with doing something useful. Though he must understand first, his understanding is for the sake of practice. 'However closely connected, the two have very different social responsibilities.

The final result of scientific investigation is a body of systematic thought. The scientific worker's responsibility is towards his fellow men of science, those who are capable of judging the value of his work; as to whether it contributes to their common system of thought. Nowadays, when science has become expensive, the man of science must eount himself lucky, if those who pay for his piping let him call his own tune. If ever he is not allowed to, science will die out, and after that technology will petrify into routine and superstition.

The technologist is the servant of the public, directly or indirectly. His business is to plan or produce things which are useful and not harmful. His best efforts may sometimes be misused by other people through no fault of his own, but he has no right to assume that misuse is never his fault. An architect planning a new housing estate, who designs a built-in cocktail bar for the houses but no accommodation suitable for children, has a great deal of responsibility for the social habits of the inhabitants. He may put forward two schemes, one with cocktail bar, the other with nursery and playroom, saying both cannot be had at the price, and leaving the choice to the politicians. But in the modern world, social problems are more and more tied up with technical matters, so that the technologist can and does force the hand of the politician far more than he used to.

The social conduct of those technologists we call medical men has been governed by a definite moral code-the Hippocratic Oath-as a result of which they have on the whole used their immense prestige for the good of the community. It has been suggested that all technologists should be bound by a kind of Hippocratic Oath. The man who has to draw up such an oath is not to be envied his task. It was easy for Hippocrates, as he dealt only with the relations between individual physician and individual patient, which are always much the same and for which a general rule can be laid down. Nowadays the technologist is concerned far more with large-scale collective relations. Each new problem is different from the last ; general rules may do more harm than good. Still, there is one great danger ahead, which if seen may be avoided. The tendency now is for men to become the servants of their machines, instead of the machines the servants of men. The engineer's formula of efficiency may be merely an excuse to further this tendency, unless he remembers that people come first and machines second.

\section{FORTHCOMING EVENTS}

(Meetings marked with an asterisk * are open to the public)

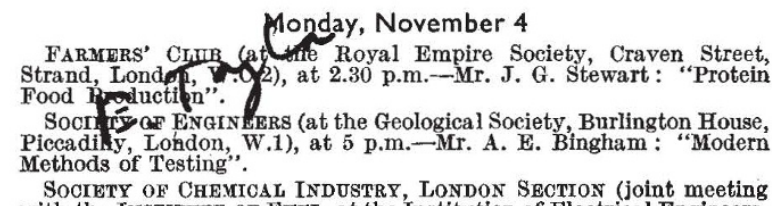

SocIETY OF CheMical INDUSTRY, LONDON SECTION (joint meeting with the INSTITUTE OF FUEL, at the Institution of Flectrical Engineers, Savoy Place, Victoria Embankment, London, W.C.2), at 6 p.m.Dr. C. C. Hall : "The Operation and Developm
Tropsch and related Processes in Germany".

Tuesday, November 5 CHADWICK PUBLIC LECTURE (in the Livingstone Hall, London
Missionary Society, 42 Broadway, Westminster, London, S.W.1), at the Age of Chadwick"." ROYAL INSTITUTION (at 21 Albemarle Street, London, W.1), at
5.15 p.m.- Prof. James Gray, F.R.S.: "Locomotory Mechanisms in Vertebrate Animals, 2, Transition from Water to Land; Origin of the Limb with Five Digits; Its Development for Propulsion and Support”.*

INSTITUTION OF CHEMICAL ENGINEERS (at the Geological Society, "Burlington House, Piccadilly, London, W.1), at 5.30 p.m.-Mr. W. F. Carey: "The Effect of Using Hot Air in Grinding Systems".

ROYAL ANTHROPOLOGICAL INSTITUTE (at 21 Bedford Square, London, W.C.1), at 5.30 p.m.--Saw Tha Din: "The Karen People", ROYAL PHOTOGRAPHIC SOCIETY, SCIENTIFIC AND TECHNICAL GROUP "How Accurate is a Photograph ?" (Contributions by Dr. J. L. Tearle, Mr. A. A. Ray and others). 